\title{
Transient myocardial ischaemia after acute myocardial infarction
}

Peter Currie, Stephen Saltissi

\begin{abstract}
The prevalence and characteristics of transient myocardial ischaemia were studied in 203 patients with recent acute myocardial infarction by both early (6.4 days) and late (38 days) ambulatory monitoring of the ST segment. Transient ST segment depression was much commoner during late (32\% patients) than early (14\%) monitoring. Most transient ischaemia ( $>85 \%$ episodes) was silent and $80 \%$ of patients had only silent episodes. During late monitoring painful ST depression was accompanied by greater ST depression and tended to occur at a higher heart rate. Late transient ischaemia showed a diurnal distribution, occurred at a higher initial heart rate, and was more often accompanied by a further increase in heart rate than early ischaemia.

Thus in the first 2 months after myocardial infarction transient ischaemia became increasingly common and more closely associated with increased myocardial oxygen demand. Because transient ischaemic episodes during early and late ambulatory monitoring have dissimilar characteristics they may also have different pathophysiologies and prognostic implications.
\end{abstract}

Current evidence suggests that important coronary artery disease frequently remains silent until the onset of a severe morbid clinical event. Thus myocardial infarction is often not preceded by angina ${ }^{1}$ and more than $50 \%$ of patients resuscitated from out of hospital ventricular fibrillation deny previous cardiac symptoms despite angiographically demonstrated clinically significant coronary artery stenoses. ${ }^{2}$ Recent attempts to identify and assess coronary disease have therefore focused on ways of detecting silent myocardial ischaemia as well as symptomatic episodes. Ambulatory ST segment monitoring is increasingly being used for this purpose because it is now widely accepted that any transient ST segment depression recorded reflects true myocardial ischaemia in patients with proven coronary artery disease..$^{3-5}$

Much is currently known about the frequency, characteristics, and significance of silent myocardial ischaemia during ambulatory monitoring in patients with both stable $^{6}$ and unstable angina ${ }^{7}$ but there is little information on patients with acute myocardial infarction. We therefore performed repeated ambulatory monitoring in 203 patients with recent acute myocardial infarction and we report the frequency and characteristics of transient myocardial ischaemia in this population.

\section{Patients and methods}

All patients admitted to the Royal Liverpool Hospital (September 1987 to December 1988) with definite acute myocardial infarction ${ }^{8}$ were considered eligible for the study unless they were in Killip class $D$, had significant valve disease, left ventricular hypertrophy, electrocardiographic conduction defects, other serious diseases, or were currently taking digitalis. Of 358 patients screened 14 refused consent, 24 died shortly after admission, and eight patients had been recruited previously. A further 109 patients were excluded because of the criteria listed above. We therefore performed ambulatory monitoring in 203 patients (152 men and 51 women, mean age 58 years (range 34-76)) with myocardial infarction.

The infarct was anterior/lateral in $93(46 \%)$ patients, inferior/posterior in $110(54 \%)$, non$Q$ wave in $47(23 \%)$, and 36 patients $(18 \%)$ were treated by thrombolysis. Forty six patients $(23 \%)$ had a previous myocardial infarction, $74(36 \%)$ had at least a 1 month history of angina pectoris, $23(11 \%)$ were diabetic, and $114(56 \%)$ were current smokers.

\section{AMBULATORY ST SEGMENT MONITORING}

Single channel ST segment monitoring was performed with the Oxford Medilog 4000-II. Previous studies ${ }^{9}$ including those in our laboratory (unpublished) showed that this real time ambulatory monitoring equipment reliably measured ST segment shift both at rest and on exercise. The single modified V5 lead (CM5) predominantly used in this study was highly sensitive for detecting exercise induced myocardial ischaemia and only rarely did a second simultaneous inferior lead detect the maximum ST change. ${ }^{1011}$

Ambulatory recordings were made both early (before discharge) and late (4-8 weeks after admission). Recording periods were limited to 24 hours because longer periodsfor example 48 hours-are more impractical and expensive and we found only occasionally detected ischaemia not apparent on a 24 hour recording. Pre-gelled electrodes (Deva Medical) were applied and skin impedence 
Table 1 Procedural details of ambulatory ST segment monitoring after myocardial infarction

\begin{tabular}{|c|c|c|c|}
\hline \multirow[b]{2}{*}{ Details } & \multicolumn{2}{|c|}{ Ambulatory monitoring } & \multirow[b]{2}{*}{$p$} \\
\hline & $\begin{array}{l}\text { Early } \\
\text { (6.4 days) (\%) }\end{array}$ & $\begin{array}{l}\text { Late } \\
\text { ( } 38 \text { days) (\%) }\end{array}$ & \\
\hline $\begin{array}{l}\text { Total patients } \\
\text { Lead position: }\end{array}$ & 201 & 177 & \\
\hline $\begin{array}{l}\text { Modified V5 } \\
\text { Modified V6 } \\
\text { CC5 } \\
\text { Others }\end{array}$ & $\begin{array}{l}185(92) \\
7(3) \\
4(2) \\
5(2)\end{array}$ & $\begin{array}{c}150(85) \\
12(7) \\
5(3) \\
10(6)\end{array}$ & \\
\hline $\begin{array}{l}\text { Recording ECG lead: } \\
\text { Q wave present } \\
\text { Beseline ST elevation } \\
\text { Baseline ST depression }\end{array}$ & $\begin{array}{l}31(15) \\
38(19) \\
44(22)\end{array}$ & $\begin{array}{c}15(8) \\
8(5) \\
19(11)\end{array}$ & $\begin{array}{l}<0.04 \\
<0.001 \\
<0.004\end{array}$ \\
\hline $\begin{array}{l}\text { Drug treatment taken during monitoring } \\
\beta \text { Blocker } \\
\text { Nitrate } \\
\text { Calcium antagonist } \\
\text { At least one drug }\end{array}$ & $\begin{array}{l}71(35) \\
41(20) \\
19(9) \\
102(51)\end{array}$ & $\begin{array}{l}28(16) \\
33(19) \\
17(10) \\
63(36)\end{array}$ & $\begin{array}{l}<0.001 \\
<0.004\end{array}$ \\
\hline
\end{tabular}

was checked (Oxford Medical Systems XI-1) to ensure a reading of less than $5 \mathrm{k} \Omega$. Before each recording, patients adopted the supine, right lateral, prone, left lateral, and standing positions and underwent a period of hyperventilation (each manoeuvre for 30 seconds). ST segment shift with posture was taken into account in the analysis (see below).

Patients were given a diary to record the times of onset and finish of symptoms and daily activities and were interviewed after monitoring to ensure that all symptoms had been recorded and any discrepancies in the diaries were corrected.

\section{ST SEGMENT ANALYSIS}

The magnetic tapes (TDK AD60 cassettes) were replayed (Oxford 4500 system) to produce a report of the ST segment and heart rate trends. The ST level while the patient was supine was usually chosen as the baseline; however, if there was $\geqslant-0.5 \mathrm{~mm}$ $(-0.05 \mathrm{mV})$ additional ST depression from the supine level during any postural manoeuvre then the maximum ST depression during such manoeuvres was used as the baseline. Episodes of ST depression were identified on the $S T$ trend and validated by examining, with X8 magnifying lens and a $0.1 \mathrm{~mm}$ graticule, electrocardiogram strips printed at each point of interest. Transient myocardial ischaemia was defined as $\geqslant 30 \mathrm{~s}$ of at least $-1.0 \mathrm{~mm}$ planar/downsloping $S T$ depression, measured at $80 \mathrm{~ms}$ after the $\mathrm{J}$ point. ${ }^{12}$ If there was baseline ST depression of

Table 2 Prevalence and characteristics of transient ST depression

\begin{tabular}{lccc}
\hline & \multicolumn{2}{l}{ Ambulatory monitoring } & \\
\cline { 2 - 4 } Variable & $\begin{array}{l}\text { Early } \\
n(\%)\end{array}$ & $\begin{array}{c}\text { Late } \\
n(\%)\end{array}$ & $p$ \\
\hline Patients with STD & $29 / 201(14)$ & $56 / 177(32)$ & $<0.001$ \\
STD duration (min) & 1102 & 2731 & \\
Total STD episodes & 107 & 280 & $<0.001$ \\
STD with HR increase & $40 / 107(37)$ & $211 / 280(75)$ & $<0.001$ \\
HR at STD onset (mean (SD)) & $82(15)$ & $99(20)$ & \\
Proportion silent STD & $91 / 107(85)$ & $264 / 280(94)$ & \\
Symptoms in patients with STD: & $24 / 29(83)$ & $48 / 56(86)$ & \\
All STD episodes silent & $3 / 29(10)$ & $5 / 56(9)$ & \\
STD sometimes symptomatic & $2 / 29(7)$ & $3 / 56(5)$ & \\
STD always with angina & &
\end{tabular}

HR, heart rate (beats/min); STD, transient ST segment depression. $\geqslant-0.5 \mathrm{~mm}$, then further $(-1.0 \mathrm{~mm}) \mathrm{ST}$ depression had to be present before ischaemia was diagnosed. Episodes of ST depression were considered to be separate if the ST shift was absent for at least 3 consecutive minutes. ST segment elevation was not used in this analysis to diagnose transient ischaemia because the diagnostic specificity of this change on ambulatory monitoring has not been well established.

The presence or absence of a significant increase in heart rate (arbitrarily chosen as $\geqslant 10$ beats/min and resembling the figure set by other workers ${ }^{3}$ ) above the adjacent baseline in association with each episode of ST depression was determined by examining the computer derived heart rate trend. The heart rate at the onset of significant ST depression and the time of onset, associated symptoms, and daily activities during such episode were noted. Daily activities were classified as mental (for example, reading or watching television), physical (for example walking, washing, dressing, housework), exertional (for example shopping and climbing stairs or hills), resting, and sleep.

\section{STATISTICAL ANALYSIS}

We compared differences in prevalence of early and late ST depression and episodes of myocardial ischaemia associated with increased heart rate by a $\chi^{2}$ test. We used the standard error of the difference between the two means to compare the heart rates at the onset of early and late ST depression and the Wilcoxon rank sum test to compare the characteristics of silent and symptomatic ischaemic episodes.

Early and late ambulatory monitoring periods were compared directly in a subgroup of patients who were taking identical medication during both recordings. The diurnal pattern of ischaemia was analysed in patients taking no antianginal drugs during ambulatory monitoring.

\section{ETHICAL CONSIDERATIONS}

The study was approved by the local ethics committee and all patients gave informed consent.

\section{Results}

BACKGROUND INFORMATION

Early ambulatory monitoring (mean 6.4 days, range 3-15) was performed in 201 patients $(99 \%)$ and late recordings (38 days, range $22-$ 93) were obtained in 177 patients $(87 \%)$. Recording lasted a mean (SD) of 23.1 (2.6) and $23.5(1.0)$ hours/patient respectively. Table 1 gives further details. $Q$ waves or baseline $S T$ segment deviation in the recording lead and concurrent $\beta$ blockade were commoner during early monitoring.

TRANSIENT MYOCARDIAL ISCHAEMIA

While transient ST depression developed on late ambulatory monitoring in one third of patients, only one in seven had such changes on 
Figure 1 (A) Diurnal variation of early transient myocardial ischaemic episodes $(-\boldsymbol{\Delta}-)$ in

patients $(n=201$ undergoing ambulatory monitoring 6.4 days after acute myocardial infarction compared with episodes in patients $(n=99)$ taking no antianginal drugs $(-\triangle-)$. (B) Diurnal variation of late transient ischaemia (-O-) in patients $(n=177)$ undergoing ambulatory monitoring 38 days after myocardial infarction compared with episodes in patients ( $n=114$ ) taking no antianginal drugs $(-\mathrm{O}-)$.

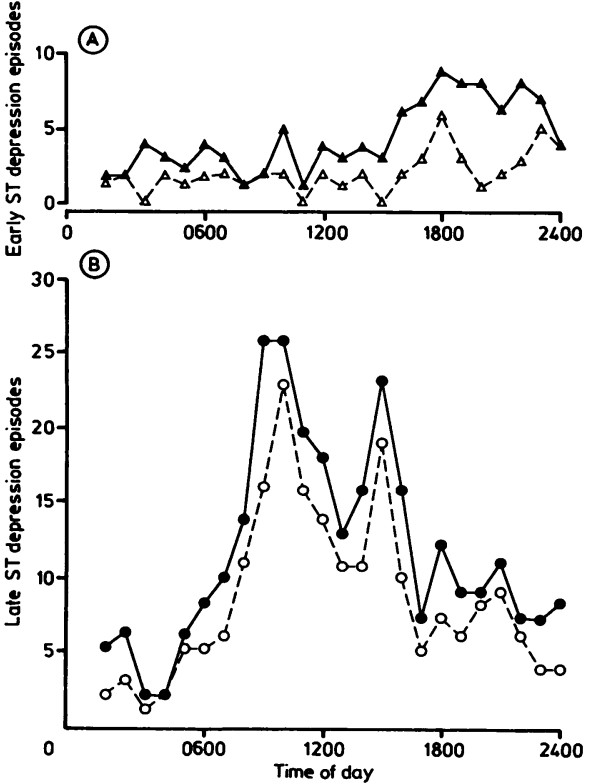

early (pre-discharge) monitoring (table 2). Later episodes occurred at a higher $(+25 \%)$ heart rate at onset and were much more commonly associated with periods of increased heart rate ( $\geqslant 10$ beats/min increase) than early ST depression. These differences between early and late ischaemic episodes were also apparent in a subgroup (101 patients) taking identical antianginal drugs during both their early and late ambulatory monitoring (see later).

The pattern of late transient ischaemia showed diurnal variation with ST depression predominating during the waking hours while the pattern of early transient ischaemia was more random-though early episodes seemed to be more common in the late afternoon and evening (fig 1). Early transient myocardial ischaemia showed little diurnal change in distribution in 99 patients who were not taking antianginal drugs during early monitoring (fig 1).

Transient ischaemia was overwhelmingly asymptomatic (table 2). In fact, $>80 \%$ of patients with either early or late ST depression showed only silent episodes; a further $10 \%$ of patients had both silent and symptomatic

Table 3 Daily activities during episodes of transient myocardial ischaemia

\begin{tabular}{llc}
\hline & \multicolumn{2}{l}{ Ambulatory monitoring } \\
\cline { 2 - 3 } Activity & $\begin{array}{l}\text { Early } \\
n(\%)\end{array}$ & $\begin{array}{l}\text { Late } \\
n(\%)\end{array}$ \\
\hline Period of rest & $47(52)$ & $71(27)$ \\
Walking & $13(14)$ & $54(21)$ \\
Low-level physical activity & $5(6)$ & $52(20)$ \\
Mental activity & $12(13)$ & $42(16)$ \\
Sleeping & $11(12)$ & $31(12)$ \\
Exertion & $2(2)$ & $13(5)$ \\
Total episodes & $90^{\star}$ & $263^{\star}$
\end{tabular}

$\star$ The associated activity was unknown in 17 early and 17 late episodes of ST depression. episodes and the remaining $10 \%$ experienced angina during all episodes of ST depression. The presence of absence of symptoms had no effect on the characteristics of early ST depression but during late monitoring symptomatic ST depression was greater $(p<0.0001)$ than the silent change in the $S T$ segment $(-1.8$ $(0.14) v-1.3(0.02) \mathrm{mm}$, mean (SEM)) and tended to occur at a higher heart rate $(105.8$ (6.9) $v$ 98.1 (1.2) beats $/ \mathrm{min}, \mathrm{p}=0.13)$. The duration of symptomatic and silent $S T$ depression did not differ significantly $(11.5(4.8) v 9 \cdot 7$ $(0.9) \min , \mathrm{p}=0.6)$.

During early monitoring most (64\%) episodes of ST depression occurred at rest or during sleep, 33\% during low level physical or mental activities, and only $2 \%$ during exertion (table 3). During later recordings, however, most $(57 \%)$ of ST change occurred at times of low level physical or mental daily activity, 39\% at rest or in sleep, and very little $(5 \%)$ was related to exertion (table 3 ).

The maximum ST depression detected during episodes of early or late transient ischaemia (fig 2) was rarely more than $-2.0 \mathrm{~mm}$; however, a small number of episodes of $S T$ change greater than $-3.0 \mathrm{~mm}$ were recorded. Most episodes of ST depression detected on early or late monitoring lasted less than 10 minutes (81/107 episodes (76\%) and $200 / 280$ $(71 \%)$ respectively) but $2-3 \%$ of episodes lasted $>1$ hour (maximum duration 107.5 minutes during early monitoring and $134 \mathrm{~min}-$ utes during late monitoring).

\section{EFFECT OF DRUG TREATMENT ON TRANSIENT ISCHAEMIA}

We identified a subgroup of 101 patients who were on identical treatment during both their early and late ambulatory recordings (table 4). Two thirds $(67 \%)$ of these patients were not taking antianginal drugs, $25 \%$ were on single agents, and $9 \%$ were taking a combination of treatments during the two recording periods. The characteristics of transient ischaemia in this subgroup resembled those of the study population as a whole-ST depression was more frequent during late recordings than during early recordings, there were significantly more episodes of ST depression related to an increase in heart rate during late monitoring than during early monitoring, and the mean heart rate at the onset of ST depression during late monitoring was also greater (table 4).

Furthermore, in this drug matched group, only 6 of the 12 patients with early ST depression developed any ST changes during late monitoring while $27(82 \%)$ of the 33 patients with late ST segment depression did not show any ST shift during early monitoring.

The diurnal pattern of transient ischaemia was also examined in those patients not taking antianginal drugs during ambulatory monitoring (99 patients during early monitoring and 114 during late monitoring). Early and late monitoring in these subgroups detected 49 and 204 ischaemic episodes respectively. The diurnal distributions of these ischaemic episodes, uninfluenced by drug treatment, were similar to that of the whole study population (fig 1). 
Figure 2 (A) Maximum $S T$ depression episodes of early transient myocardial ischaemia in patients $(n=201)$ undergoing ambulatory monitoring 6.4 days after myocardial infarction. (B) Maximum $S T$ depression during transient ischaemia detected in patients ( $n=177$ ) undergoing ambulatory monitoring 38 days after myocardial infarction. $(1 \mathrm{~mm}=0.1 \mathrm{mV})$ during
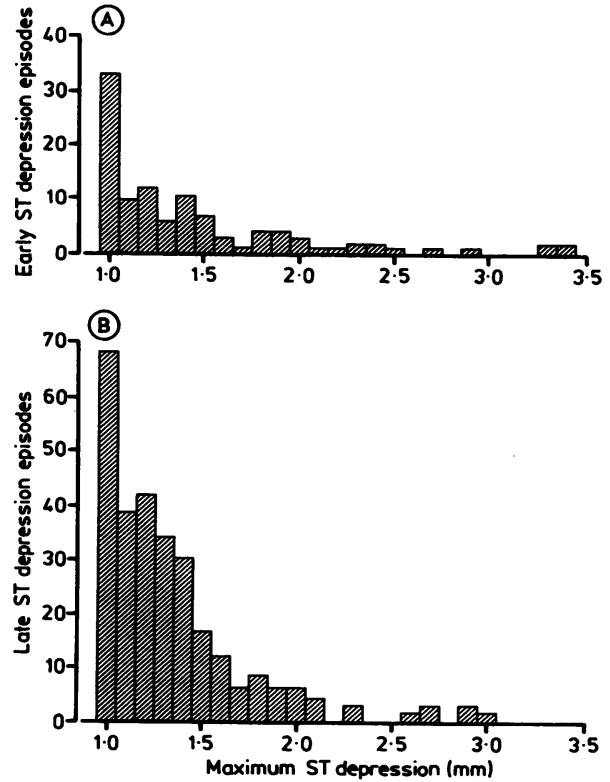

The relatively small number (49) of episodes of ST depression during early monitoring means that interpretation of the data remains uncertain.

Seventy one patients were taking $\beta$ blockers during early ambulatory monitoring; in six late monitoring was not performed and 48 stopped taking the drug during late monitoring. In this latter group transient ST depression was commoner $(p<0.04)$ during late monitoring than during early monitoring ( $16 / 48$ patients $(33 \%)$ $v 7 / 48(15 \%))$. In $17 / 71$ patients who were taking $\beta$ blockers during both recordings transient ST depression was equally common early and late (three and two patients).

\section{INFLUENCE OF INFARCT CATEGORY, THROMBOLYTIC TREATMENT, AND DIABETES MELLITUS}

The prevalence of transient myocardial ischaemia during both early and late monitoring was independent of infarct site or the presence of $Q$ waves and was not increased in diabetic patients or in patients treated by thrombolysis.

Table 4 Ambulatory ST segment monitoring in patients taking identical treatments during early and late recordings

\begin{tabular}{|c|c|c|c|}
\hline \multirow[b]{2}{*}{ Details } & \multicolumn{2}{|c|}{ Ambulatory monitoring } & \multirow[b]{2}{*}{$p$} \\
\hline & $\begin{array}{l}\text { Early } \\
n(\%)\end{array}$ & $\begin{array}{l}\text { Late } \\
n(\%)\end{array}$ & \\
\hline Total patients & 101 & 101 & \\
\hline $\begin{array}{l}\text { Treatment during monitoring: } \\
\text { Single drug } \\
\beta \text { Blocker } \\
\text { Nitrate } \\
\text { Calcium antagonist } \\
\text { Combined drug treatment } \\
\text { Two drugs } \\
\text { Three drugs } \\
\text { No drug treatment } \\
\text { Patients with STD } \\
\text { Duration of STD (min) } \\
\text { Total STD episodes } \\
\text { Proportion of silent STD } \\
\text { STD with HR increase } \\
\text { HR at STD onset (mean (SD)) }\end{array}$ & $\begin{array}{l}25(25) \\
10(10) \\
13(13) \\
2(2) \\
9(9) \\
8(8) \\
1(1) \\
67(67) \\
12 / 101(12) \\
434 \\
40 \\
33 / 40(83) \\
17 / 40(43) \\
85(13)\end{array}$ & $\begin{array}{l}25(25) \\
10(10) \\
13(13) \\
2(2) \\
9(9) \\
8(8) \\
1(1) \\
67(67) \\
33 / 101(33) \\
1639 \\
161 \\
155 / 161(96) \\
108 / 161(67) \\
100(21)\end{array}$ & $\begin{array}{l}0.001 \\
0.005 \\
0.005 \\
0.001\end{array}$ \\
\hline
\end{tabular}

HR, heart rate in beats/min; STD, transient ST depression.
Discussion

Silent myocardial ischaemia can cause ventricular arrhythmias, ${ }^{13}$ sudden death, ${ }^{2}$ or myocardial infarction ${ }^{14}$ and may lead to cumulative impairment of left ventricular function. ${ }^{15}$

Recently the prevalence of silent ischaemia has been studied by ambulatory monitoring in various subgroups with coronary disease $\mathrm{e}^{61617}$; patients with recent acute myocardial infarction, however, have received little attention. Bigger et al detected ischaemic ST segment changes in $28 \%$ of 50 patients during ambulatory monitoring at 3 months after myocardial infarction; surprisingly, none of these episodes was symptomatic. ${ }^{18}$ During predischarge ambulatory monitoring in 103 patients with myocardial infarction Gottlieb $e t$ al also detected ischaemic ST segment changes in 30 patients $(29 \%)$-mostly silent-and this group experienced a threefold increase in mortality at one year. ${ }^{19}$ The study patients were a highly selected population, however, in whom left ventricular ejection fraction was $<40 \%$.

In the largely unselected group of patients in this study transient ST depression was present during both early and late ambulatory monitoring-though it was considerably more frequent later $(33 \% v 12 \%)$. This difference probably largely reflects greater patient activity and hence greater myocardial oxygen demand during the later phase of recovery from myocardial infarction; and indeed many episodes $(46 \%)$ of ST depression during late recordings were associated with some degree of physical activity whereas on the predischarge tapes $77 \%$ of such episodes occurred without any accompanying physical exertion. Some of the difference may, however, be artefactual in that the high prevalence of pre-existing and unresolved baseline ST shift (either elevation or depression) in the monitoring lead during early recordings (table 1) may have masked further significant ST depression. The timing of ambulatory monitoring after myocardial infarction may therefore be crucial. If the recording is made too early, the sensitivity of the test may be poor but if the detection of silent ischaemia after myocardial infarction is to be of prognostic value and to have a beneficial influence on treatment then monitoring cannot be delayed too long, because a high proportion of cardiac events occur in the early weeks after infarction. ${ }^{20}$ Nearly all $(90 \%)$ transient ischaemic episodes detected both in this study and in that of Bigger et al ${ }^{18}$ were silent and indeed in $80 \%$ of patients showing ST depression all episodes were symptomless. Thus a greater proportion of ischaemic episodes are silent in patients shortly after myocardial infarction than in other subgroups with coronary artery disease. Although silent and painful episodes were similar in many respects, painful episodes were associated with a significantly greater degree of ST depression on recordings at 4-8 weeks after infarction.

We found a distinct pattern of diurnal variation in the incidence of transient ischaemia late after myocardial infarction which resembled that seen by others, ${ }^{621}$ with most episodes occurring in the morning. This circadian cycle is likely to be related both to the known 
variation of plasma catecholamines ${ }^{22}$ with corresponding changes in vasomotor ton $\mathrm{e}^{23}$ and the variation of heart rate and blood pressure ${ }^{24}$ with accompanying increases in myocardial oxygen demand.

Interestingly ST depression on early monitoring showed little circadian variation (fig 1 ). The explanation of this feature is not clear but it may reflect an equalisation of myocardial oxygen demand during convalescence in hospital or possibly a loss early after infarction of diurnal variation in substances affecting coronary supply. Increased prescription of $\beta$ blockers during early ambulatory monitoring may be partly responsible because others have shown a similar circadian distribution (with a tendency to afternoon and evening ischaemia) in patients with angina on drug treatment. ${ }^{25}$ Even so, during early monitoring we did not see a morning predominance of early transient ischaemia even in patients who were not taking drugs.

In this study very few ischaemic episodes occurred during physical exertions that were vigorous enough to increase myocardial oxygen demand and cause ischaemia. This suggests that coexisting changes in coronary arterial supply may be having an effect. Perhaps at times of high coronary tone-for example in the mornings, even small increases in myocardial oxygen demand may cause ischaemia whereas the same increase in demand when coronary tone is lower may produce no ischaemia. The incidence of ischaemia as well as its temporal distribution may thus depend on the interplay between factors affecting both myocardial oxygen supply and demand. Furthermore, since early transient ST depression occurred at a lower heart rate and with less frequent increase in heart rate than that on later recordings (table 4), a reduced coronary supply early after myocardial infarction may be of greater pathophysiological importance than late changes.

The reduced occurrence of transient $S T$ depression in patients in whom treatment with $\beta$ blockers continued during late ambulatory monitoring suggests that increased myocardial oxygen demand may be important in the pathophysiology of late transient myocardial ischaemia and offers a possible explanation for the known benefits of $\beta$ blockers after myocardial infarction-abolition of silent transient ischaemia.

What was the effect of concurrent drug treatment on the prevalence and characteristics of ST segment change? More patients were taking antianginal medication (especially $\beta$ blockers) on early monitoring. None the less, the frequency and characteristics of early and late transient ischaemia in a subgroup taking identical treatment during both recordings (table 4) were similar to those of the population as a whole, and the overall diurnal pattern of ischaemia (fig 1) resembled that seen in patients not having drug treatment; but the number of patients studied was too small for a definite conclusion to be reached.

Our study showed that predominantly silent transient ischaemia was detected by ambulatory ST segment monitoring in a high proportion of patients shortly after acute myocardial infarction and defined its characteristics. The relation of this transient ischaemia to exercise induced ischaemia, left ventricular function, ventricular arrhythmias, and prognosis is being studied further.

We thank the British Heart Foundation and the Mersey Regional Health Authority for financial support and the Cardiorespiratory Department at the Royal Liverpool Hospital for technical assistance.

1 Matsuda M, Matsuda Y, Ogawa H, Moritani K, Kusukawa R. Angina pectoris before and during acute myocardial infarction: relation to degree of physical activity. Am J infarction: relation to de

2 Sharma B, Francis G, Hodges M, Asinger R. Demonstration of exercise-induced ischaemia without angina in patients who recover from out of hospital ventricular fibrillation [Abstract]. Am J Cardiol 1981;47:445.

3 Deanfield JE, Selwyn AP, Chierchia S, et al. Myocardial ischaemia during daily life in patients with stable angina: its relation to symptoms and heart rate changes. Lancet 1983;i:753-8.

4 Levy RD, Shapiro LM, Wright C, Mockus LJ, Fox KM The haemodynamic significance of asymptomatic ST segment depression assessed by ambulatory pulmonary artery pressure monitoring. Br Heart $J$ 1986;56:526-30.

5 Chierchia S, Lazzari M, Freedman B, Brunelli C, Maseri A. Impairment of myocardial perfusion and function during painless myocardial ischaemia. J Am Coll Cardiol 1983 1:924-30.

6 Mulcahy D, Keegan J, Crean P, et al. Silent myocardial ischaemia in chronic stable angina: a study of its frequency and characteristics in 150 patients. Br Heart $J 1988$; 60:417-23.

7 Gottlieb SO, Weisfeldt ML, Ouyang P, Mellits LD, Gerstenblith G. Silent ischaemia as a marker for early unfavourable outcomes in patients with unstable angina un Engl J Med 1986;314:1214-9.

8 Report of the Joint International Society and Federation of Cardiology/World Health Organisation Task Force on Cardiology/World Health Organisation Task Force on
Standardisation of Clinical Nomenclature. Nomenclature Standardisation of Clinical Nomenclature. Nomenclature
and criteria for diagnosis of ischemic heart disease. and criteria for diagnosis
Circulation 1979;59:607-9.

9 Silber S, Vogler AC, Spiegelsberger F, Vogel M, Theisen K. Validation of digital Holter ST segment analysis. Journal of Ambulatory Monitoring 1988;1:145-52.

10 Quyyumi AA, Crake T, Mockus LJ, Wright CA, Rickards AF, Fox KM. Value of the bipolar lead CM5 in electrocardiography. Br Heart $J$ 1986;56:372-6.

11 Egstrup $K$. The relationship between $S T$ segment deviation projected to the front of the chest during exercise and simultaneous Holter monitoring. Eur Heart J. 1988;9: 412-7.

12 Quyyumi AA, Crake T, Wright C, Mockus L, Fox K. The role of ambulatory ST-segment monitoring in the diagnosis of coronary artery disease: comparison with exercise testing and thallium scintigraphy. Eur Heart $J 1987$ 8:124-9.

13 Hohnloser SH, Kasper W, Zehender M, Geibel A, Meinertz $\mathrm{T}$, Just $\mathrm{H}$. Silent myocardial ischaemia as a predisposing factor for ventricular fibrillation. Am J Cardiol 1988, 61:461-3.

14 Kannel WB, Sorlie P, McNamara PM. Prognosis after initia myocardial infarction. The Framingham Study. $\mathrm{Am}$ Cardiol 1979;44:53-9.

15 Geft IL, Fishbein MC, Ninomiyal K, et al. Intermittent brief periods of ischaemia have a cumulative effect and may cause myocardial necrosis. Circulation 1982;66: may cause

16 Stern S, Gavish A, Weisz G, Benhorin J, Keren A, Tzivoni D. Characteristics of silent and symptomatic myocardial ischaemia during daily activities. Am J Cardiol 1988; 61:1223-8.

17 Weidinger F, Sochor H, Czernin J, Pospischil E, Glogar D. Characteristics of transient ischaemic episodes in patients with silent and symptomatic exercise-induced myocardia ischaemia. Eur Heart $J$ 1988;9:1081-7.

18 Bigger T, Moss A, and the multicenter post infarction trial investigators. Silent ischaemia after myocardial infarction [Abstract]. J Am Coll Cardiol 1987;9:68A.

19 Gottlieb SO, Gottlieb SH, Achuff SC, et al. Silent ischaemia on holter monitoring predicts mortality in high-risk on holter monitoring predicts mortality in high

20 De Feyter PJ, Van Eenige MJ, Dighton DH, Visser FC. Prognostic value of exercise testing, coronary angiography
Proper Prognostic value of exercise testing, coronary angiography
and left ventriculography, 6-8 weeks after myocardial and left ventriculography, 6-8 weeks
infarction. Circulation 1982;66: 527-36.

21 Rocco MB, Barry J, Campbell S, et al. Circadian variation of transient myocardial ischaemia. Circulation 1987;75: 395-400.

22 Turton $\mathbf{M B}$, Deegan $T$. Circadian variation of plasma catecholamines, cortisol and immunoreactive insulin concentrations in supine subjects. Clin Chim Acta 1974 55:389-97.

23 Rozanski A, Berman DS. Silent myocardial ischaemia. I Pathophysiology, frequency of occurrence, and approaches toward detection. Am Heart $J$ 1987;114:615-26.

24 Millar-Craig MW, Bishop CN, Raferty EB. Circadian variation of blood pressure. Lancet 1978;i:795-7.

25 Mulcahy D, Keegan J, Lindsay D, et al. Silent myocardia schaemia in patients referred for coronary bypass surger because of angina: a comparison with patients whose symptoms were well controlled on medical treatment. $B r$ Heart J 1989;61:496-501. 